\title{
Task-type and Listening Ability of Iranian Male Learners
}

\author{
Muhammad Reza Nasirian \\ Islamic Azad University, Shahreza Branch, Iran \\ Email: Mreza.nasirian@yahoo.com
}

\begin{abstract}
This present study investigated the correlation between four specific task-types (matching, form-filling, labeling, and selecting) and listening ability of the students of English as a foreign language. This study not only identified correspondence between four specific task-types and students' language proficiency level, but also tried to find out whether there was any significant relationship between tasktype and listening ability of Iranian male learners. Forty-five EFL male learners participated in this study. The instruments of data collection of this correlational study included one language proficiency test and one task-based test of listening comprehension. Analysis of the findings indicated that there was significant positive relationship between listening ability and all four tasks. In terms of correspondence, labeling, selection and matching tasks had high correspondence to advanced and lower intermediate proficiency levels, but only matching task corresponded to upper-intermediate proficiency level. Incorporating tasks and task-based activities in EFL classrooms seem to have enhanced the listening comprehension ability of EFL learners.
\end{abstract}

Index Terms - task-type, listening comprehension, correspondence

\section{INTRODUCTION}

Foreign language listening comprehension is a complex and active process and crucial in the development of second language competence; but until recently, this important skill had been neglected both with regard to its place in language teaching and with regard to the creation and development of useful techniques and procedures for teaching the listening skill.

This negligence may have stemmed from the fact that listening is considered a passive skill, and from the belief that merely exposing the student to the spoken language is sufficient for improvement of listening comprehension (Carter \& Nunan, 2001).

But by the emergence of Communicative Language Teaching (CLT) in language teaching methodology, communicative competence became the end goal of any learning and teaching program. According to CLT, all four skills of language are equally important and listening skill is not a secondary skill, but an active and internal one. Among recent manifestations of communicative language teaching, task-based language teaching (TBLT) has emerged as a major focal point of language teaching which is based on using tasks as the core of language teaching and learning (Brown, 2007).

Listening effectively is frequently cited as the most difficult part of acquiring another language and yet, without good listening skills, communication can be fractured. According to Ur (1984) listening exercises are most successful if they are constructed around a task. The students should demonstrate their understanding by performing the intended act of the speaker and if they can complete the assigned task correctly, their listening ability will improve. Listening tasks, therefore, seem to be corresponded with students' skills in listening, as well as reading, writing, and speaking.

\section{Task-based Language Teaching}

The idea and meaning of task is not as simple as it might seem. There are many definitions of tasks in many disciplines; a clear cut definition of which has turned into a problem .In spite of the vast quantity of the published materials on task-based language learning and teaching, there is no consensus definition of what a task is? (Bruton, 2002).

Williams and Burden (1997) define task as "any activity learners engage to further the process of learning a language" (p. 168).

Similarly, Long (1985; as cited in Ellis, 2003) defines task as the hundred and one things people do in every day life for themselves or for others freely or for some rewards.

Task-based language learning (TBLL), also known as task-based language teaching (TBLT) or task-based instruction (TBI) refers to an approach based on the use of tasks as the core unit of planning and instruction in language teaching. This approach focuses on the use of authentic language and on asking students to do meaningful tasks using the target language (Richards \& Rodgers, 2001).

The purpose of this study is to test the practical usefulness of task-based approach in teaching listening and to determine the correspondence of four specific task-types and three different proficiency levels. Because the 
previous studies in this regard had hardly dealt with applying the tasks designed by the researcher, this study afforded exclusivity to the literature in the sense that it encompassed the four specific task types.

This study attempted to answer the following questions:

Is there any significant relationship between task type and listening ability of Iranian male learners?

Is there any direct correspondence between task-type and proficiency level of EFL learners?

\section{Methodology}

\section{A. Participants}

This is a correlational study in which the participants were chosen from among the EFL learners of a total of sixty male students, all of whom were Persian native speakers but studied English more than five semesters and were Junior High- School or pre-university students. The age of all participants ranged from 15 to 22 . The rationale for selecting this range of participants was the relative familiarity with English and with listening comprehension skill. After administering a proficiency test and according to the obtained results, forty five students were chosen and put into three levels of intermediate, upper-intermediate, and advanced. This division was based on the OPT scale. Students whose scores fell between 150 and 169 were assigned as advanced learners, students with scores of 135 and 149 as upper-intermediate group and students with scores between 120 and 134 as lower intermediate group. So, participants of this study were three groups of EFL learners with three different proficiency levels.

\section{B. Instrumentation}

\section{Pre-test}

The pretest of the study was an Oxford Placement Test. This test was administered at the beginning of the study in order to place the participants into three different proficiency levels. This test is divided into two main sections, Listening test and Grammar test.

\section{Listening Test}

This listening part involves 100 items taken from authentic situations where mishearings have taken place. The students have in front of them in written form, the items being tested and must make their choices on the basis of what they hear on the tape. The 100 items are on the cassette, spoken by native speakers at normal speaking speed. The listening test takes ten or twelve minutes. Each item is read only once and there was not any pause or repetition.

\section{Grammar Test}

The grammar test was a 100-item written multiple-choice test of a range of grammatical and lexical items .The items of the grammar test are contextualized situationally or linguistically and took a maximum of 50 minutes. This test is presented in two parts. Within each part there are short sub-sections with different context. Students can answer the questions by simply ticking the correct box.

Post-test

The post-test in this study was a task-based test of listening comprehension (Cameron, 2000) to determine the efficacy of the task types on the listening comprehension of EFL learners and to see whether there were any significant relationships between the tasks and students' language proficiency level.

\section{Procedure}

The study was conducted at the start of the term. At first, an OPT test was administered and then the participants were divided into three groups. This way, there were three groups of lower intermediate, upperintermediate, and advanced. After placing them into three groups, they were given special listening tasks for the whole term that took eighteen sessions ( 9 weeks).

Each session lasted about 80 minutes and 40 minutes was allotted to teaching listening by the intended tasks and the time was equally divided among the four tasks.

In fact, special listening tasks were designed for each group to be practiced through the task-based approach. The four tasks were labeling, selecting, matching, and form filling, which were applied according to the framework introduced in Richards and Renandya (2002, p. 244). The four tasks were practiced by each of the three groups of participants by the help of another book of Cameron and Todd entitled" Prepare for IELTS General Training Modules (2001). This book also contains five listening tests and suggests some useful points for learners. Because the four tasks specified in this study were purely receptive ones and there was no demand on the subjects' part for language production, the validity of the tasks was protected.

Concerning the selection of listening materials that would fit each level of proficiency appropriately, Scrivener (1994) argued that it is not the material (the recording) that should set the level of the lesson, it is the task. Thus, a tape of someone asking for directions in the street is more likely to be usable at a lower level than a discussion on complex moral issues. In this study the four types of tasks were practiced by each of the three groups, and they only differed regarding the topic and language system (grammar and vocabulary). Cameron (2001) claims that these types of tasks are quite suitable for all levels of language proficiency. 
With regard to the sequence of class activities, the following route-map was made and implemented throughout the course:

Lead in: The teacher introduced the topic (foregrounding) and the students performed a similar task so that the task requirements are made clear. Next, the teacher prepared students for what they are to hear by pre-listening activities that are probably the most important aspect of any listening sequence because the success of all the other activities depends on the extent to which the teacher manages to give the students the background, guidance and direction to achieve the end goal of the activity (Chastain, 1988).

There are some pre-listening strategies that were recommended by the teacher at the beginning of first session. The pre-listening strategies are:

Anticipate the words and phrases you are most likely to hear.

Anticipate synonyms and ideas expressed in different words.

It is not necessary to understand all of the words.

Pre-task work: included looking through worksheet, work on vocabulary, prediction.

The actual task: involved performing each of the four actual task types of the study.

In this stage the students listen to the material. One of the most important problems during this stage is to arouse learners' interest in the content of the listening materials (Bahrami, n. d).

Tape playing: When the students are completely ready and motivated for the new lesson and after some predictions and working on similar and related vocabularies, the actual task stage begins. The teacher first played the tape and then asked the students to perform the task individually. If they could not achieve the point individually, the teacher would play the tape a number of times so that the students could discover the correct words and compare their findings in pairs or in groups after each time of playing. This strategy will be repeated until students could discover the exact words and could obtain the teacher's approval. Eventually, if they could not find it, the teacher provided the exact word.

Prabhu (1987) stated that learners must be encouraged to complete the task on their own, so they should be provided with such a chance, but working collaboratively on tasks would enable learners to perform beyond the capacities of any individual learner.

As far as task sequencing was concerned, the tasks and materials were graded so as to facilitate maximum learning. In effect, this required determining the complexity of individual task types so that tasks would match to learners' level of development.

It is necessary to mention that four tasks of the study (Matching, Form Filling, Labeling, and Selection) have many common features. So, controlling task complexity is easy. The proficiency level of students has been controlled carefully and the same methodological procedures were applied by the teachers for the implementation of the four tasks.

The students were invited to consider different strategies in performing each task. For form filling task, read the form carefully and think of how the words will sound when you hear them, but do not cling too tightly to your predictions. For matching and selection task, it is better for learners to anticipate the vocabulary and ideas you might hear.

\section{Data Analysis}

In order to obtain the relationship and correspondence between each task- type and proficiency level of participants, correlational analysis was performed. In this study, the Pearson Correlation was used.

\section{FINDINGS}

In order to find out whether the whole treatment (task-based activities) affected the participants' performance (listening comprehension) in the three levels of language proficiency, the obtained data will be subjected to the statistical analysis of Pearson correlation with the following null hypotheses:

$\mathrm{H}_{01}$ There is no significant relationship between task type and listening ability of EFL male learners.

$\mathrm{H}_{02}$ There is no direct correspondence between task type and proficiency level of EFL learners.

In order to test the first hypothesis, a number of correlational computations were employed. The results are provided below for each proficiency group separately. Table 1 shows the results of the correlation between listening ability and task types for the advanced group.

TABLE 1

THE RESUltS OF THE CORRELATION BETWEEN LISTENING ABILITY AND TASK TYPES FOR THE ADVANCED GROUP

\begin{tabular}{llllll}
\hline & & Form Filling & Labeling & Matching & Selection \\
\hline Listening ability & Pearson Correlation & .482 & $.782^{* *}$ & $.866^{* *}$ & $.721^{* *}$ \\
& Sig. (2-tailed) & .069 & .001 & .000 & .002 \\
& $\mathrm{~N}$ & 15 & 15 & 15 & 15 \\
\hline
\end{tabular}

*. Correlation is significant at the 0.05 level (2-tailed)

**. Correlation is significant at the 0.01 level (2-tailed). 
According to Table 1, for the advanced group the correlation between listening ability and form filling task is not significant $(\mathrm{r}=.482, \mathrm{p}=.69)$. On the other hand, there are significant correlations between listening ability and Labeling $(r=.782, p=.001)$, Matching $(r=.866, p=.000)$, and Selection $(r=.721, p=.002)$. Therefore, in advanced group, the first null hypothesis is retained with respect to Form Filling, but it is rejected for Labeling, Matching, and Selection.

Table 2 indicates the results of the correlational analysis between listening ability and task types for the upperintermediate group.

TABLE 2

THE RESULTS OF THE CORRELATION BETWEEN LISTENING ABILITY AND TASK TYPES FOR THE UPPER-INTERMEDIATE GROUP

\begin{tabular}{llllll}
\hline & & Form Filling & Labeling & Matching & Selection \\
\hline Listening Proficiency & Pearson Correlation & $.772^{* *}$ & $.790^{* *}$ & $.755^{* *}$ & $.758^{* *}$ \\
& Sig. (2-tailed) & .001 & .000 & .001 & .001 \\
& $\mathrm{~N}$ & 15 & 15 & 15 & 15 \\
\hline
\end{tabular}

It can be seen in the above table, Table 2, that there are significant correlations between listening ability and all four task types, that is, Form Filling $(r=.772, p=.001)$, Labeling $(r=.790, p=.000)$, Matching $(r=.755, p=.001)$, and Selection $(r=.758, p=.001)$. As a result, the first null hypothesis is rejected with regard to upper-intermediate group.

The last correlational analysis for testing the first null hypothesis was performed for the lower-intermediate group. Table 3 depicts the results of this correlation.

TABLE 3

THE RESULTS OF THE CORRELATION BETWEEN LISTENING ABILITY AND TASK TYPES FOR THE LOWER-INTERMEDIATE GROUP

\begin{tabular}{llllll}
\hline & & Form Filling & Labeling & Matching & Selection \\
\hline Listening Proficiency & Pearson Correlation & $.593^{*}$ & $.852^{* *}$ & $.758^{* *}$ & $.710^{* *}$ \\
& Sig. (2-tailed) & .020 & .000 & .001 & .003 \\
& $\mathrm{~N}$ & 15 & 15 & 15 & 15 \\
\hline
\end{tabular}

By studying Table 3, one can see that, as with upper-intermediate group, the correlations between listening ability and all task types are statistically significant, that is, Form Filling $(r=.593, p=.020)$, Labeling $(r=.852$, $\mathrm{p}=.000)$, Matching $(\mathrm{r}=.758, \mathrm{p}=.001)$, and Selection $(\mathrm{r}=.710, \mathrm{p}=.003)$. As a result, the first null hypothesis is rejected with regard to upper-intermediate group. So, the first null hypothesis is rejected, and it can be claimed that there is a significant correlation between task type and listening ability of EFL learners.

For testing the second null hypothesis of the study, another set of correlational analyses were employed. The results are presented below for each proficiency group separately.

Table 4 shows the results of the correlation between proficiency scores and task type scores for the advanced group.

TABLE 4

THE RESULTS OF THE CORRELATION BETWEEN PROFICIENCY AND TASK TYPES FOR THE ADVANCED GROUP

\begin{tabular}{|c|c|c|c|c|c|}
\hline & & Form Filling & Labeling & Matching & Selection \\
\hline \multirow[t]{3}{*}{ Proficiency } & Pearson Correlation & .339 & $.781^{* *}$ & $.737^{* *}$ & $.592^{*}$ \\
\hline & Sig. (2-tailed) & .217 & .001 & .002 & .020 \\
\hline & $\mathrm{N}$ & 15 & 15 & 15 & 15 \\
\hline
\end{tabular}

By referring to Table 4 , one understands that for the advanced group the correlation between proficiency scores and Form Filling task is not significant $(\mathrm{r}=.339, \mathrm{p}=.217)$. On the other hand, there are significant correlations between listening ability and Labeling $(r=.781, p=.001)$, Matching $(r=.737, p=.002)$, and Selection $(r=.592$, $p=$. 020). Therefore, in advanced group, the second null hypothesis is retained with respect to Form Filling, but it is rejected regarding Labeling, Matching, and Selection.

Table 5 indicates the results of the correlational analysis between proficiency and task types for the upperintermediate group. 
TABLE 5

THE RESULTS OF THE CORRELATION BETWEEN PROFICIENCY AND TASK TYPES FOR THE UPPER-INTERMEDIATE GROUP

\begin{tabular}{|c|c|c|c|c|c|}
\hline & & Form Filling & Labeling & Matching & Selection \\
\hline \multirow[t]{3}{*}{ Proficiency } & Pearson Correlation & .428 & .440 & $.699^{* *}$ & .444 \\
\hline & Sig. (2-tailed) & .111 & .101 & .004 & .097 \\
\hline & $\mathrm{N}$ & 15 & 15 & 15 & 15 \\
\hline
\end{tabular}

Table 5 reveals that there is only a significant correlation between proficiency and matching $(r=.699, p=.004)$, but the correlations between proficiency and other tasks, that is, Form Filling $(r=.428, p=.111)$, Labeling $(r=.440$, $\mathrm{p}=.101)$, and Selection $(\mathrm{r}=.444, \mathrm{p}=.97)$, are not statistically significant. As a result, the second null hypothesis is rejected with regard to matching task, but it is retained for Form Filling, Labeling, and Selection tasks.

The last correlational computation for the second null hypothesis was performed for the lower-intermediate group. Table 6 indicates the results for this correlation.

TABLE 6

THE RESULTS OF THE CORRELATION BETWEEN PROFICIENCY AND TASK TYPES FOR THE LOWER-INTERMEDIATE GROUP

\begin{tabular}{llllc}
\multicolumn{2}{c}{ THE RESULTS OF THE CORRELATION BETWEEN PROFICIENCY AND TASK TYPES FOR THE LOWER-INTERMEDIATE GROUP } \\
\hline
\end{tabular}

Looking at Table 6, it can be seen that, as with the advanced group, the correlations between proficiency scores and Form Filling task is not significant $(\mathrm{r}=.246, \mathrm{p}=.376)$, but there are significant correlations between proficiency scores and Labeling $(\mathrm{r}=.835, \mathrm{p}=.000)$, Matching $(\mathrm{r}=.604, \mathrm{p}=.017)$, and Selection $(\mathrm{r}=.874, \mathrm{p}=.000)$. Therefore, in lower-intermediate group, the second null hypothesis is retained with respect to Form Filling, but it is rejected regarding Labeling, Matching, and Selection. According to the above results, the second null hypothesis is rejected in advanced and lower-intermediate group, but it is retained in upper-intermediate group.

\section{DISCUSSION}

As far as the first question of the study is concerned, the researcher embarked upon discovering the relationship between each task and the listening comprehension of the EFL learners. The results obtained rejected the first null hypothesis for the three tasks of "matching, labeling and selection," and it was verified for the "form-filling" task for advanced group of the study. This means that there was a significant relationship between the first three tasks and listening comprehension ability of advanced group. On the other hand, no such relationship was observed between the task of "form-filling" and listening comprehension. But the correlations between listening ability and all four task types for lower-intermediate and upper-intermediate groups are statistically significant. So, the first null hypothesis is rejected with regard to upper-intermediate and lower-intermediate groups.

The second research question of the study wants to know if there is any direct correspondence between task type and proficiency level of EFL learners.

By investigating the obtained results, it can be seen that, in lower- intermediate and advanced groups, the correlations between proficiency scores and Form Filling task is not significant, but there are significant correlations between proficiency scores and Labeling, Matching, and Selection. But in upper-intermediate group, there is only a significant correlation between proficiency and matching, but the correlations between proficiency and other tasks, that is, Form Filling, Labeling, and Selection , are not statistically significant. So, labeling task, matching task and selection task correspond to the lower-intermediate and advanced proficiency level and only matching task corresponds to the upper-intermediate proficiency level. Totally and according to the above results, the second null hypothesis is rejected in advanced and lower-intermediate group, but it is retained in upperintermediate group. The results suggest that there is high correspondence between labeling, selection and matching task types and advanced and lower-intermediate proficiency levels. In other words, Labeling, Matching, and Selection tasks are more suitable and compatible for lower-intermediate and advanced group, but only the matching task is suitable for upper-intermediate proficiency level.

In a similar study performed by Bahrami (n. d), the influence of task-based activities on listening ability of EFL learners was examined. The participants of that study were ninety senior EFL learners and the sources of data for this quasi-experimental study included two task-based tests of listening comprehension and a test of language proficiency entitled an Examination for the Certificate of Proficiency in English (ECPE) test. The results of this study demonstrated that at the intermediate level, all the tasks showed some degrees of correspondence with the level in question except the task of selecting. In the upper-intermediate level, all the tasks corresponded with this 
level except the "selecting" task. And finally, in the advanced level, the two tasks of "matching" and "labeling" showed correspondence to the level in question, and the two others did not.

\section{CONCLUSION}

Listening comprehension is a complex psychological activity that involves various mechanisms. Feyten (1991) claims that more than $45 \%$ of communicating time is listening, which clearly shows how important this skill is in overall language ability. Different methods have been tested to promote listening ability of EFL learners in Iran, but unfortunately most EFL learners suffer from listening problems. This study is an attempt to demonstrate the effectiveness of four specific task types in teaching listening comprehension skill and to see if there is any direct correspondence between four specific task types and proficiency level of students. So, forty-five male learners of a private language institute in three different proficiency levels were taught by the help of four task types. Implementing aural task-based materials in the language classroom exposed EFL students to real-language use from the beginning of language study.

Generally speaking, according to the obtained results, the listening-comprehension skill in EFL students tended to improve through exposure to task-based input. Specifically, there is significant positive correlation between listening ability and all four tasks. In terms of correspondence, labeling, selection and matching tasks have high correspondence to advanced and lower intermediate proficiency levels, but only matching task corresponds to upper-intermediate proficiency level. This study implied that each task type has special properties and according to the characteristics of each task it is more suitable for specific proficiency level. According to the obtained results through this experiment, the researcher arrived at the following conclusions:

1- Incorporating tasks and task- based activities in EFL classrooms enhance the listening comprehension skill of learners and task-based teaching of listening may be a suitable and effective alternative for traditional methods of teaching listening. Of course, some task types are more suitable for specific proficiency levels. For best result, it is better to teach listening by tasks that have high correspondency to the learners' proficiency level.

2- It seems that the Iranian EFL course books do not adequately prepare students for task-based instruction due to the fact that they focus excessively on language forms and traditional methods of teaching listening. So, the result of this study and others indicate that helping students make connections to the real world and authentic tasks might facilitate listening comprehension

\section{REFERENCES}

[1] Bahrami, M. (n.d). The Effect of Task Types on EFL Learners' Listening Ability. Islamic Azad University, Iran. Retrieved August 10, 2011 from: http://www.kon.org/urc/v9/bahrami.html

[2] Brown, H. D. (2007). Principles of Language Learning and Teaching. Fifth Edition. Pearson Longman.

[3] Bruton, A. (2002). From Tasking Purposes to Purposing Tasks. ELT journal .Retrieved August 15, 2011, from: http://eltj.oxfordjournals.org/content/56/3/280.abstract?sid=49c4bd80-f8a3-454f-8c93-604fe6f6dca9

[4] Cameron, P. \& Todd, V. (2001). Prepare for IELTS: The IELTS preparation course. Sydney: University of Technology.

[5] Carter, R. and Nunan, D. (2001). The Cambridge Guide to Teaching English to Speakers of Other languages. Cambridge University Press.

[6] Chastain, K. (1988). Developing second language skills: theory and practice. (3rd ed.). Florida: Harcourt brace Jovanovich Publishers.

[7] Ellis, R. (2003). Task-based language learning and teaching. Oxford: Oxford University Press

[8] Feyten, C. (1991). The power of listening ability: an overlooked dimension in language acquisition. The Modern Language Journal, 75 (2): 173-180.

[9] Prabhu, N.S. (1987). Second language Pedagogy. Oxford: Oxford University Press

[10] Richards, J. C. and Rodgers, T. S. (2001). Approaches and Methods in Language Teaching. Cambridge Language Teaching Library.

[11] Richards, J. C. \& Renandya, W. A. (2002). Methodology in language teaching: An anthology of current practice. Cambridge: Cambridge University Press.

[12] Scrivener, J. (1994). Learning teaching. Oxford: Macmillan Heinemann English Language Teaching.

[13] Ur, P. (1984). Teaching Listening Comprehension. New York: Cambridge University Press.

[14] William, M. \& Bruden, R. L. (1997). Psychology for Language Teachers. A social Constructivist Approach. Cambridge: Cambridge University Press

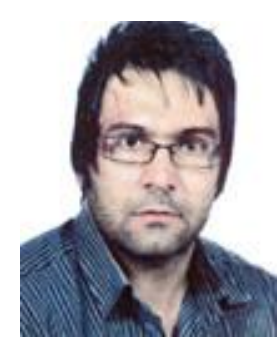

Mohammad Reza Nasirian born in Iran, Isfahan province. Date of Birth: 1980.

Degrees: Master of Art (English Teaching methodology). 2011. Iran, Islamic Azad University, Shahreza Branch. Bachelor of Art (English Translation Course). 2005. Iran, Islamic Azad University, Shahreza Branch.

He teaches English in different Language institutes of Shahreza. He worked in Kolbe publication for two years. 